\title{
Posterior reversible encephalopathy syndrome following a thoracic discectomy-induced dural leak: case report
}

\author{
Lisa B. E. Shields, MD, ${ }^{1,2}$ John R. Johnson, MD, ${ }^{2}$ and Christopher B. Shields, MD ${ }^{1-3}$ \\ ${ }^{1}$ Norton Neuroscience Institute, ${ }^{2}$ Norton Healthcare; and ${ }^{3}$ Department of Anatomical Science and Neurobiology, University of \\ Louisville, School of Medicine, Louisville, Kentucky
}

\begin{abstract}
Posterior reversible encephalopathy syndrome (PRES) is a clinicoradiological syndrome characterized by headaches, altered mental status, seizures, and visual disturbances. Classic MRI findings include white matter changes of the parietooccipital regions. This syndrome has been encountered in myriad medical illnesses, including hypertension, preeclampsia/eclampsia, and immunosuppressive conditions. While the pathogenesis of the disorder is unclear, vasoconstriction and hypoperfusion leading to brain ischemia and vasogenic edema have been implicated as potential mechanisms. The authors present, to the best of their knowledge, the first case of PRES following a thoracic spinal surgery-induced dural leak noted on resection of the fifth rib during a thoracotomy for a T4-5 discectomy. Brain MRI revealed large areas of increased FLAIR and T2 hyperintensity in the superior posterior frontal lobes, superior and medial parietal lobes, and bilateral occipital lobes. Following repair of the CSF leak, the patient's symptoms resolved. Spinal surgeons should be alert to the potentially life-threatening condition of PRES, especially in a hypertensive patient who experiences surgeryinduced dural leakage. The development of a severe positional headache with neurological signs is a red flag that suggests the presence of PRES. Prompt attention to the diagnosis and treatment of this condition by repairing the dural leak via surgery or expeditious blood patch increases the likelihood of a favorable outcome.
\end{abstract}

http://thejns.org/doi/abs/10.3171/2016.4.SPINE1623

KEY WORDS discectomy; dural leak; thoracic; posterior reversible encephalopathy syndrome; PRES

I NITIALLY described by Hinchey and colleagues in 1996, reversible posterior leukoencephalopathy syndrome, currently known as "posterior reversible encephalopathy syndrome" (PRES), refers to a clinicoradiological syndrome marked by headaches, altered mental status, seizures, and visual abnormalities, with severe cases leading to coma and death. ${ }^{2,16,23,35}$ Radiological findings consist of white matter vasogenic edema involving the frontal, parietal, and occipital lobes, demonstrated as increased T2 and FLAIR signal intensity on MRI. ${ }^{8,16,23,24,30,35}$ Fluid-attenuated inversion recovery imaging facilitates diagnosis and detects subcortical and cortical lesions in PRES.? The syndrome can be caused by a sudden, sustained rise in blood pressure exceeding the upper limit of cerebral blood flow autoregulation. ${ }^{23}$ Both hypertension ${ }^{23,35}$ and preeclampsia/eclampsia ${ }^{22,23,34}$ have been linked to PRES. Several additional immunosuppressive medical conditions and medications are associated with PRES, including chemotherapy in cancer, ${ }^{9,24,39}$ human immunodeficiency virus (HIV), ${ }^{33,36}$ sickle cell anemia, ${ }^{32}$ and immunosuppressive drugs following transplantation. ${ }^{15,20,29}$ Posterior reversible encephalopathy syndrome has been reported in a hypertensive patient with spinal epidural hematoma ${ }^{40}$ and in a patient with subarachnoid hemorrhage due to a ruptured intracranial aneurysm. ${ }^{21}$ The syndrome has also been observed in children, primarily those with hematological or neoplastic disorders or renal diseases and after transplantation. . $^{11,18,19,27,43}$

We present a unique case of PRES caused by a dural leak that occurred on resection of the fifth rib during an anterior approach for a T4-5 discectomy. The pathogenesis and mechanism of PRES are also described.

\section{Case Report}

History and Examination

A 47-year-old woman (height 5'11.5", weight 186 pounds [84.37 kg]; body mass index [BMI] $25.58 \mathrm{~kg} / \mathrm{m}^{2}$ ) presented with an 8-month history of thoracic pain and a 2-month history of left leg weakness, numbness in both feet, and poor balance. She had well-controlled hypertension, hyperthyroidism, and a 30 pack-year smoking his-

ABBREVIATIONS BBB = blood-brain barrier; PRES = posterior reversible encephalopathy syndrome; TAA = thoracic aortic aneurysm; TAAA = thoracoabdominal aortic aneurysm. 
tory. Thoracic MRI demonstrated a large disc herniation at T4-5 with left-sided spinal cord compression (Fig. 1).

\section{First Surgery}

A left thoracotomy was performed with removal of the rib heads of T-4 and T-5, which created a CSF leak along the T-5 nerve root sleeve. The leak subsided spontaneously without repair. A prolonged Valsalva maneuver did not cause further CSF leakage. Because of the severe stenosis of T4-5, 75\% of each vertebral body adjacent to the T4-5 herniated disc was removed to provide adequate decompression above and below the large sequestered disc (Fig. 2). A bone-filled cage (Amendia Inc.) was inserted between T-3 and T-6.

\section{First Postsurgical Course}

Postoperatively, the patient had severe positional headaches suggestive of a CSF leak. Three days following the anterior procedure, a T2-8 posterior thoracic fusion was performed. The positional headaches persisted; therefore, a lumbar drain was inserted in an attempt to close the CSF leak. Cerebrospinal fluid $(100 \mathrm{ml})$ drained over the next several hours, after which the patient experienced prolonged tonic-clonic seizures lasting for 10 minutes. There had been no history of seizures. The lumbar drain was occluded. After a prolonged postictal state for 4 days, the patient complained of visual loss as well as severe disorientation and confusion. The postural headaches persisted. The CSF leak persisted for 14 days prior to the final CSF repair. The delay in the repair was due to the severe neurological deficits exhibited by the patient.

Brain MRI demonstrated increased FLAIR and T2 hyperintensity diffusely over the superior posterior frontal, superior and medial parietal, and bilateral occipital lobes (Fig. 3). This appearance confirmed the diagnosis of PRES.

\section{Second Surgery}

A left posterior thoracic laminectomy of T-5 was performed to repair the CSF leak. Cerebrospinal fluid emanated from the distal portion of the T-5 nerve root sheath. The T-5 nerve root was ligated close to the dural tube.

\section{Second Postsurgical Course}

The patient's headaches resolved postoperatively. Her mental status returned to normal, and she was discharged with complaints of mildly blurred vision. Brain MRI performed 5 days later showed dramatic improvement of the FLAIR signal changes (Fig. 4A). An MR image obtained 6 weeks later showed minimal residual occipital lobe abnormality (Fig. 4B).

\section{Discussion}

Posterior reversible encephalopathy syndrome has been reported following lumbar puncture in the obstetric setting, ${ }^{10,17,31,41}$ for suspected chronic adult hydrocephalus, ${ }^{13}$ and during a workup for multiple sclerosis. ${ }^{28}$ In addition, a renal transplant recipient developed PRES following the inadvertent placement of an epidural catheter, which resulted in a CSF leak..$^{29}$ Post-lumbar puncture headaches

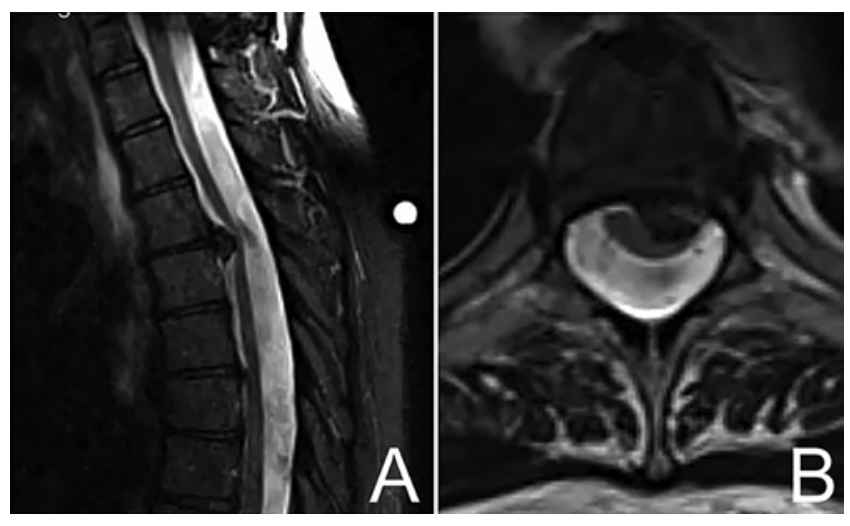

FIG. 1. Sagittal (A) and axial (B) T2-weighted MR images demonstrate a large midline disc herniation with slight left eccentricity at T4-5.

after attempted epidural anesthesia during labor have led to PRES. . $^{1017,31,41,44}$ Headaches following a lumbar puncture are the result of a transdural CSF leak causing decreased CSF pressure and reflex dilation of the intracranial blood vessels. ${ }^{28}$ The headaches of PRES and those following lumbar puncture are similar, which may delay the accurate diagnosis and treatment of PRES. . $^{10,41}$

Timely recognition and treatment of PRES is critical in reversing the potentially fatal clinical outcome and radiological abnormalities. ${ }^{23,35,37}$ Alhilali et al. investigated the risk factors leading to death in their study of 47 patients who developed PRES. ${ }^{2}$ Nine patients (19.1\%) succumbed to the neurological effects of PRES. Fatalities increased 5-fold with intraparenchymal or subarachnoid hemorrhage and doubled with low CSF glucose (mean $36 \mathrm{mg} / 100 \mathrm{ml}$, range $30-45 \mathrm{mg} / 100 \mathrm{ml}$ ). Hypertensive encephalopathy was associated with a fatal outcome, while eclampsia was protective with a $75 \%$ decreased risk.

Two theories have been proposed to explain PRES: 1) severe hypertension leading to a loss of cerebral autoregulation, brain hyperperfusion, and endothelial injury/ vasogenic edema, and 2) cerebrovascular vasoconstriction and hypoperfusion causing cerebral ischemia and vasogenic edema. ${ }^{4,26}$ The latter theory is believed most likely. ${ }^{4,6}$ Perfusion MRI demonstrates an increase in the diffusion coefficient as well as a decrease in cerebral blood volume and cerebral blood flow in the posterior cerebral territory in patients with PRES, supporting the theory of disturbed cerebral autoregulation leading to vasoconstriction. ${ }^{6}$ Brubaker and colleagues suggest that interstitial edema may be caused by the elevation of capillary hydrostatic pressure mediated by venous constriction. ${ }^{6}$ Alternatively, the immune system may trigger endothelial activation that initiates a molecular cascade. ${ }^{26}$ This theory postulates that molecules (for example, cytokines, vascular endothelial growth factor [VEGF]) are produced and alter homeostasis of the blood-brain barrier (BBB), leading to a loss of tight junction integrity causing fluid transudation and vasogenic edema. According to that theory, the cause of PRES is not related to hypertension. ${ }^{26}$

Blood pressure is normal in $20 \%-30 \%$ of patients with PRES. ${ }^{5,38}$ The syndrome is often encountered in toxemia of pregnancy (eclampsia), 22,23,34,38 chemotherapy in cancer, ${ }^{9,24,39}$ transplantation, ${ }^{15,20,29}$ and infection..$^{33,36}$ Common 

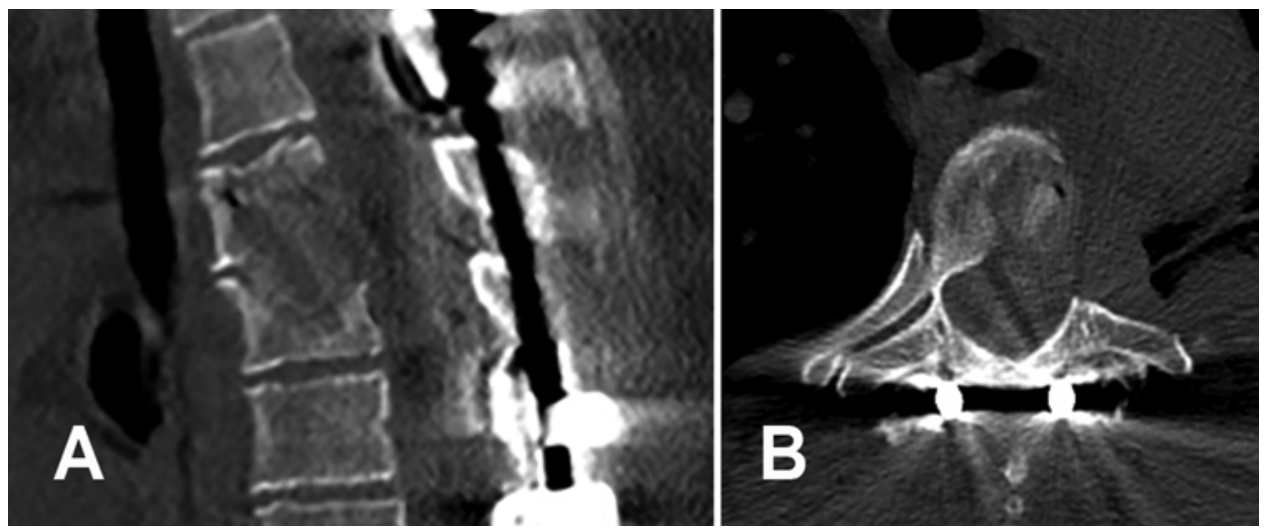

FIG. 2. Postoperative thoracic CT scan of the surgical site, sagittal (A) and axial (B) views, demonstrating the vertebral body resection cavity, spinal reconstruction, and fixation.

biological processes include 1) immune system activation of T cells, 2) endothelial cell activation, 3) endothelial injury, 4) vascular instability (systemic vasoconstriction), and 5) organ hypoperfusion. ${ }^{4}$ Cerebral hypoperfusion is observed on imaging studies with symmetric vasogenic edema between the lateral and medial cerebral territory (watershed distribution). ${ }^{3,4}$

Our report of a CSF leak caused by resection of the head of the fifth rib during an anterior thoracic exposure for a T4-5 discectomy and subsequent CSF drainage aids in clarifying the etiology of PRES. Our case is similar to the gynecological setting in which an inadvertent CSF leak (wet tap) occurs during an epidural block. The mechanism of PRES is presumably related to a pressure differential between the cerebral arterial pulse pressure and the CSF pressure. The pulse pressure refers to the difference between the systolic and diastolic pressure readings and is measured in $\mathrm{mm} \mathrm{Hg}$. Normal CSF pressure measured in the lumbar subarachnoid space in the recumbent position is $100-180 \mathrm{~mm} \mathrm{H}_{2} \mathrm{O}(8-15 \mathrm{~mm} \mathrm{Hg}){ }^{1}$ Posterior reversible encephalopathy syndrome is marked by dysfunction of the cerebral circulation. When the difference between the pulse pressure greatly exceeds the CSF pressure, a breakdown of the BBB in the posterior circulation occurs, as is reflected by the MRI abnormalities.

Spinal fluid drainage via a lumbar puncture during thoracic (TAA) and thoracoabdominal (TAAA) aortic aneurysm repair has been found to decrease the likelihood of spinal cord ischemia and paraplegia. ${ }^{12,14,42}$ Wynn et al. used spinal drains in 486 of 648 patients who underwent TAA or TAAA repair and reduced CSF pressure to $<6$ $\mathrm{mm} \mathrm{Hg}$ during thoracic aortic occlusion and reperfusion..$^{42}$ After surgery, spinal fluid pressure was maintained at $<10$ $\mathrm{mm} \mathrm{Hg}$ until patients were awake with normal leg function. These authors stressed the importance of low spinal fluid pressure to decrease the risk of spinal cord ischemia leading to paraplegia. In another report, prompt CSF drainage reversed an individual's paraplegia that had occurred following an elective abdominal endovascular aneurysm repair. ${ }^{25}$

The pulse pressure and spinal cord blood flow are significantly decreased when the aorta is clamped during aortic aneurysm repair. Low CSF pressure in combination with decreased spinal cord pulse pressure decreases the likelihood of postoperative spinal cord infarction. Although spinal drainage is beneficial during TAA and TAAA surgery, this mechanism contrasts with the deleterious effect following low CSF pressure that may cause PRES.

In our case of CSF hypotension due to a dural leak, a significant difference occured between pulse pressure in the brain and CSF pressure. This disparity between pulse pressure and CSF pressure presumably led to the clinico-
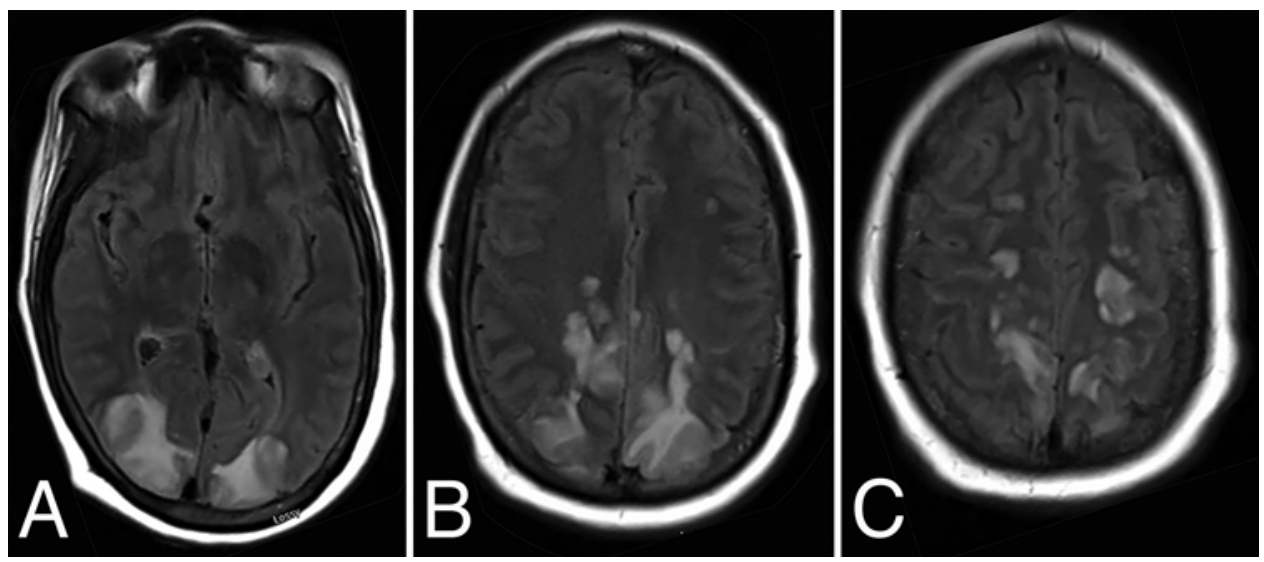

FIG. 3. Brain MRI reveals evidence of large areas of increased FLAIR and T2 hyperintensity in the bilateral occipital lobes (A), superior and medial parietal lobes (B), and superior posterior frontal lobes (C). 


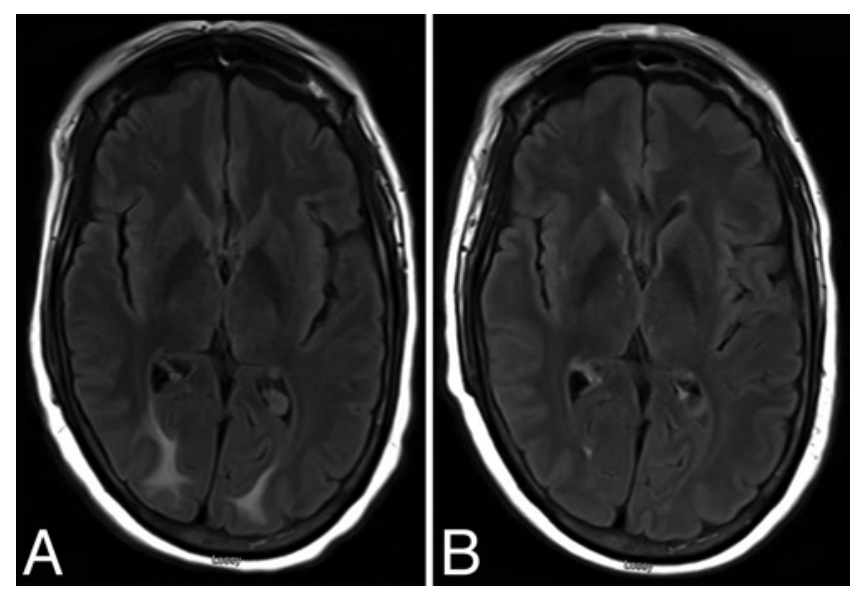

FIG. 4. Brain MRI (A) 5 days after repair of the CSF leak demonstrates marked improvement of the FLAIR signal changes within the posterior parietal and occipital lobes. Brain MRI (B) 6 weeks later shows further improvement with minimal white matter changes in the parieto-occipital lobe.

radiological scenario of PRES. After the pressure differentials were normalized in PRES following dural repair of the CSF leak, the patient's symptoms and pathognomonic MRI appearance resolved. Factors that make certain patients vulnerable to this pressure differential scenario are unknown.

Following spine surgery, many CSF leaks will subside spontaneously with or without a lumbar CSF drain. If necessary, drains can remain in place for several days. That was the rationale for placing the lumbar subarachnoid drain in our case; however, the neurological deficit (seizures, blindness, coma) developed within hours of placing the drain because of the additional removal of CSF through the drain. Thus, the drain was promptly removed. The delay in the repair of the CSF leak was due to the severe neurological deficits exhibited by the patient following the tonic-clonic seizure. The major contribution of this paper is to call attention to the rare complication of a postoperative CSF leak, namely PRES. If a CSF leak leads to the development of PRES, then direct closure of the leak should be performed when the patient is medically stable.

\section{Conclusions}

Spinal surgeons should be aware of the potentially lifethreatening condition of PRES, particularly in the setting of a hypertensive patient who experiences a surgery-induced dural leak. The development of an excessive positional headache with neurological signs is a warning sign that suggests the presence of PRES. Prompt attention to the diagnosis and treatment of this entity by repairing the dural leak via surgery or expeditious blood patch increases the likelihood of a favorable outcome.

\section{Acknowledgments} port.

We acknowledge Norton Healthcare for their continued sup-

\section{References}

1. Agamanolis DP: The normal CSF. Neuropathology. (http://
neuropathology-web.org/chapter14/chapter14CSF.html). [Accessed April 19, 2016]

2. Alhilali LM, Reynolds AR, Fakhran S: A multi-disciplinary model of risk factors for fatal outcome in posterior reversible encephalopathy syndrome. J Neurol Sci 347:59-65, 2014

3. Bartynski WS: Posterior reversible encephalopathy syndrome, part 1: fundamental imaging and clinical features. AJNR Am J Neuroradiol 29:1036-1042, 2008

4. Bartynski WS: Posterior reversible encephalopathy syndrome, part 2: controversies surrounding pathophysiology of vasogenic edema. AJNR Am J Neuroradiol 29:1043-1049, 2008

5. Bartynski WS, Zeigler Z, Spearman MP, Lin L, Shadduck RK, Lister J: Etiology of cortical and white matter lesions in cyclosporin-A and FK-506 neurotoxicity. AJNR Am J Neuroradiol 22:1901-1914, 2001

6. Brubaker LM, Smith JK, Lee YZ, Lin W, Castillo M: Hemodynamic and permeability changes in posterior reversible encephalopathy syndrome measured by dynamic susceptibility perfusion-weighted MR imaging. AJNR Am J Neuroradiol 26:825-830, 2005

7. Casey SO, Sampaio RC, Michel E, Truwit CL: Posterior reversible encephalopathy syndrome: utility of fluid-attenuated inversion recovery MR imaging in the detection of cortical and subcortical lesions. AJNR Am J Neuroradiol 21:11991206, 2000

8. Covarrubias DJ, Luetmer PH, Campeau NG: Posterior reversible encephalopathy syndrome: prognostic utility of quantitative diffusion-weighted MR images. AJNR Am J Neuroradiol 23:1038-1048, 2002

9. Dedić Plavetić N, Rakušić Z, Ozretić D, Simetić L, Krpan AM, Bišof V: Fatal outcome of posterior "reversible" encephalopathy syndrome in metastatic colorectal carcinoma after irinotecan and fluoropyrimidine chemotherapy regimen. World J Surg Oncol 12:264, 2014

10. Doherty H, Hameed S, Ahmed I, Russell IF: Post-dural puncture headache and posterior reversible encephalopathy syndrome: a misdiagnosis or co-presentation? Int J Obstet Anesth 23:279-282, 2014

11. El-Naggari MA, Al-Nabhani D, El-Nour I, El-Manzalawy A, Abdelmogheth AA: Posterior reversible encephalopathy syndrome in two Omani children with underlying renal diseases. Sultan Qaboos Univ Med J 15:e424-e428, 2015

12. Field M, Doolan J, Safar M, Kuduvalli M, Oo A, Mills K, et al: The safe use of spinal drains in thoracic aortic surgery. Interact Cardiovasc Thorac Surg 13:557-565, 2011

13. Grelat M, Debaux JB, Sautreaux JL: Posterior reversible encephalopathy syndrome after depletive lumbar puncture: a case report. J Med Case Reports 8:261, 2014

14. Hanna JM, Andersen ND, Aziz H, Shah AA, McCann RL, Hughes GC: Results with selective preoperative lumbar drain placement for thoracic endovascular aortic repair. Ann Thorac Surg 95:1968-1975, 2013

15. Hayes D Jr, Adler B, Turner TL, Mansour HM: Alternative tacrolimus and sirolimus regimen associated with rapid resolution of posterior reversible encephalopathy syndrome after lung transplantation. Pediatr Neurol 50:272-275, 2014

16. Hinchey J, Chaves C, Appignani B, Breen J, Pao L, Wang A, et al: A reversible posterior leukoencephalopathy syndrome. N Engl J Med 334:494-500, 1996

17. Ho CM, Chan KH: Posterior reversible encephalopathy syndrome with vasospasm in a postpartum woman after postdural puncture headache following spinal anesthesia. Anesth Analg 105:770-772, 2007

18. Hodzic E, Brcic M, Atic M, Halilcevic A, Jasarevic A, Aleckovic-Halilovic M, et al: Posterior reversible encephalopathy syndrome (PRES) as a complication of immunosuppressive therapy in renal transplantation in children. Med Arh 68:218-220, 2014 
19. Khan RB, Sadighi ZS, Zabrowski J, Gajjar A, Jeha S: Imaging patterns and outcome of posterior reversible encephalopathy syndrome during childhood cancer treatment. Pediatr Blood Cancer 63:523-526, 2016

20. Kulkarni RN, Saxen SK, Hartalkar A: Post renal transplant posterior reversible encephalopathy syndrome. J Assoc Physicians India 61:743-745, 2013

21. Kuroda H, Kashimura H, Murakami T, Endo H, Mase T, Ogasawara K: Early onset of PRES in a patient with a subarachnoid haemorrhage due to a ruptured intracranial aneurysm. Br J Neurosurg 28:785-786, 2014

22. Kutlesič MS, Kutlesič RM, Koratevič GP: Posterior reversible encephalopathy syndrome in eclamptic patients: neuroradiological manifestation, pathogenesis and management. Med Pregl 68:53-58, 2015

23. Lamy C, Oppenheim C, Mas JL: Posterior reversible encephalopathy syndrome. Handb Clin Neurol 121:1687-1701, 2014

24. Le EM, Loghin ME: Posterior reversible encephalopathy syndrome: a neurologic phenomenon in cancer patients. Curr Oncol Rep 16:383, 2014

25. Lioupis C, Tyrrell M, Valenti D: A report of spinal cord ischemia following endovascular aneurysm repair of an aneurysm with a large thrombus burden and complex iliac anatomy. Vasc Endovascular Surg 44:56-60, 2010

26. Marra A, Vargas M, Striano P, Del Guercio L, Buonanno P, Servillo G: Posterior reversible encephalopathy syndrome: the endothelial hypotheses. Med Hypotheses 82:619-622, 2014

27. Masetti R, Cordelli DM, Zama D, Vendemini F, Biagi C, Franzoni E, et al: PRES in children undergoing hematopoietic stem cell or solid organ transplantation. Pediatrics 135:890-901, 2015

28. Ortiz GA, Bianchi NA, Tiede MP, Bhatia RG: Posterior reversible encephalopathy syndrome after intravenous caffeine for post-lumbar puncture headaches. AJNR Am J Neuroradiol 30:586-587, 2009

29. Pradhan A, Jairam A, Kumar RS, Srivastava A, Srivastava A, Sreevastava D, et al: Posterior reversible encephalopathy syndrome posttransplantation: a case report of possible association with cerebrospinal fluid leak after epidural catheterization. Transplant Proc 41:1957-1960, 2009

30. Provenzale JM, Petrella JR, Cruz LC Jr, Wong JC, Engelter S, Barboriak DP: Quantitative assessment of diffusion abnormalities in posterior reversible encephalopathy syndrome. AJNR Am J Neuroradiol 22:1455-1461, 2001

31. Pugliese S, Finocchi V, Borgia ML, Nania C, Della Vella B, Pierallini A, et al: Intracranial hypotension and PRES: case report. J Headache Pain 11:437-440, 2010

32. Raj S, Killinger J, Overby P: Blood transfusion in sickle cell disease leading to posterior reversible encephalopathy syndrome (PRES). J Child Neurol 28:1284-1286, 2013

33. Ribeiro S, Monteiro M, Moreira B, Franca M: Rare posterior reversible encephalopathy syndrome in a patient with HIV. BMJ Case Rep 2013:bcr2013201495, 2013

34. Rijal JP, Giri S, Dawadi S, Dahal KV: Posterior reversible encephalopathy syndrome (PRES) in a patient with late postpartum eclampsia. BMJ Case Rep 2014:bcr2013203162, 2014
35. Rykken JB, McKinney AM: Posterior reversible encephalopathy syndrome. Semin Ultrasound CT MR 35:118-135, 2014

36. Sasson SC, Oon A, Chagantri J, Brew BJ, Carr A: Posterior reversible encephalopathy syndrome (PRES) in an HIV-1 infected patient with disseminated varicella zoster virus: a case report. BMC Infect Dis 13:396, 2013

37. Servillo G, Apicella E, Striano P: Posterior reversible encephalopathy syndrome (PRES) in the parturient with preeclampsia after inadvertent dural puncture. Int J Obstet Anesth 17:88-89, 2008

38. Sibai BM: Eclampsia. VI. Maternal-perinatal outcome in 254 consecutive cases. Am J Obstet Gynecol 163:1049-1055, 1990

39. Silzle T, Glaser-Gallion N, Hitz F: Posterior reversible encephalopathy syndrome during induction chemotherapy for acute myeloid leukaemia. Eur J Haematol 92:90, 2014

40. Striano P, Striano S, Servillo G, Bifulco F, Tortora F, Caranci F, et al: Posterior reversible encephalopathy syndrome and spinal epidural haematoma in a hypertensive patient. Eur $\mathbf{J}$ Anaesthesiol 24:1065-1067, 2007

41. Torrillo TM, Bronster DJ, Beilin Y: Delayed diagnosis of posterior reversible encephalopathy syndrome (PRES) in a parturient with preeclampsia after inadvertent dural puncture. Int J Obstet Anesth 16:171-174, 2007

42. Wynn MM, Mell MW, Tefera G, Hoch JR, Acher CW: Complications of spinal fluid drainage in thoracoabdominal aortic aneurysm repair: a report of 486 patients treated from 1987 to 2008. J Vasc Surg 49:29-35, 2009

43. Yamamoto H, Natsume J, Kidokoro H, Ishihara N, Suzuki $\mathrm{M}$, Tsuji T, et al: Clinical and neuroimaging findings in children with posterior reversible encephalopathy syndrome. Eur J Paediatr Neurol 19:672-678, 2015

44. Yang Y, Wang JM, Zhou HW, Wu J, Zhang HL: Intracranial hypotension and PRES. J Headache Pain 11:447, 449, 2010 (Letter)

\section{Disclosures}

Drs. C. B. Shields and Johnson receive royalties from Amendia, Inc.

\section{Author Contributions}

Conception and design: CB Shields, LBE Shields. Acquisition of data: all authors. Analysis and interpretation of data: all authors. Drafting the article: all authors. Critically revising the article: all authors. Reviewed submitted version of manuscript: all authors. Approved the final version of the manuscript on behalf of all authors: CB Shields. Administrative/technical/material support: CB Shields, LBE Shields. Study supervision: CB Shields, LBE Shields.

\section{Correspondence}

Christopher B. Shields, Norton Neuroscience Institute, 210 East Gray St., Ste. 1102, Louisville, KY 40202. email: cbshields1@ gmail.com. 